\title{
Pedro Henríquez Ureña, profesor en la Argentina
}

$\mathrm{H}^{\mathrm{n}}$ E leído más de una vez en publicaciones hispanoamerica-

nas artículos que conjeturaban acerca de los motivos que pudo tener Pedro Henríquez Ureña para radicarse definitivamente en la Argentina, y alguna del país ha expuesto con inexactitud la forma en que se incorporó a nuestro medio. $\mathrm{Mi}$ intervención directa y, puedo decirlo, exclusiva, en las gestiones preparatorias, fueron conocidas por varios amigos comunes; al contarla ahora creo contribuir a documentar la biografía del maestro. Pero, ¿ cómo prescindir del pronombre de primera persona sin quitarle al relato valor testimonial y aserción responsable. El precepto pascaliano, vigilante con sus ojillos de diéresis, me coarta : "le moi est haissable". Sí, el yo es detestable; mas los rodeos para evitarlo suelen impedir la claridad, y sin ésta toda información es equívoca.

Mi relación personal con los hermanos Henríquez Ureña empezó con Max, quien me envió un ejemplar de su libro Tres poetas de la música. Acabo de verificar la data en la dedicatoria manuscrita: Santiago de Cuba, 7 de abril de 1918. Nos cruzamos dos o tres cartas. En el verano de 1921 vino a Buenos Aires; yo me encontraba de vacaciones en el campo y a mi regreso él había partido. Ese mismo año se realizó en México un congreso internacional de estudiantes americanos al que concurrieron cinco platenses, entre ellos dos ex alumnos míos del Colegio Nacional de La Plata, Héctor Ripa Alberdi y Arnaldo Orfila Reynal. El primero, ya autor de un libro de ver-sos - Soledad, 1920—, volvió por el Pacífico y reencendió ante 
los compañeros estudiantiles de Lima, con verbo lírico, la prédica "reformista" de aquella hora, que él había hecho encandecer ante los compañeros mexicanos. Apenas llegó a nuestra ciudad, me visitó en mi casa. Desbordaba de impresiones y recuerdos : mares, tierras, hombres ... Me traía un saludo de Pedro Henríquez Ureña y habló con particular efusión del gran dominicano residente en la capital de México.

-Es un hombre tan sencillo y bondadoso - me dijo-que, a pesar de la diferencia de edades y la altura de su posición intelectual, era como un camarada de todos los estudiantes... Intimó mucho con los argentinos. Yo tengo con él una deuda conmovedora: fjgúrese que me ha propuesto escribir un largo trabajo en colaboración...

$\mathrm{Al}$ año siguiente llegó Pedro Henríquez Ureña a Buenos Aires, integrando la misión mexicana presidida por el ministro de educación José Vasconcelos, enviada para asistir a la trasmisión del mando presidencial. Yo me había radicado aquel año en la capital federal. Mis dos ex alumnos me presentaron en seguida a su amigo. Al oír que éste se tuteaba con Orfila debí hacer un gesto de sorpresa, porque en cuanto nos hallamos solos, mi visitante se creyó obligado a explicarme aquella familiaridad:

-Durante la permanencia en México de estos jóvenes, su "voseo" me tentó a emplearlo en broma con ellos, y así quedó establecido inesperadamente nuestro tuteo. Lo singular es que yo me he tuteado con pocos amigos antiguos y de mi edad.

Agregó que la familiaridad entre los estudiantes argentinos y él se había acentuado en paseos y excursiones, durante los cuales solía pedirles que le entonasen canciones populares de nuestra tierra, siempre interesado por conocer las particularidades folklóricas de América. No era ése el fuerte de nuestros jóvenes representantes. $Y$ sonrió al recordar la desafinación de uno, las confusiones de otro, la sorpresa de un tercero que no se explicaba aquella curiosidad insólita...

Estrechamos amistad rápidamente. Nos veíamos a diario. Juntos recorrimos el salón primaveral de Bellas Artes, asistimos a recepciones y banquetes y viajamos a La Plata, donde se celebró un acto universitario en homenaje a la misión mexicana y otro, el 14 de octubre, en la Facultad de Humanida- 
des, donde Henríquez Ureña leyó las preciosas y memorables páginas que tituló La utopía de América. Tuve yo la satisfacción de presentarlo al auditorio en nombre del cuerpo de profesores. La embajada, compuesta sobre todo por destacadas figuras de las letras, atraía el interés de los centros de la cultura porteña. Era ministro de México el gran poeta Enrique González Martínez, siempre entusiasta y cordial; Vasconcelos no se negaba, por cierto, a disertar en público; Julio Torri leía relatos sutiles; Carlos Pellicer recitaba su canto reciente a las cataratas del Iguazú ; Henríquez Ureña, reclamado por la concurrencia, solía decir su breve glosa a un pensamiento de Rabindranath Tagore. Una noche manifestó el deseo de ver actuar a Roberto Casaux y fuímos a la ópera donde trabajaba el celebrado cómico.

Al partir de regreso la misión, mi nuevo amigo se despidió de mí con un promisorio i hasta pronto! Encariñado con la Argentina, ya me había expresado su esperanza de radicarse en ella.

Nuestra correspondiencia epistolar se inició con una carta suya datada en México el 20 de marzo de 1923. Extraigo de ella esta declaración estilística: "A poco de llegar aquí -tardamos dos meses- le envié Mi España, que espero le haya llegado y le haya llevado mis recuerdos, como yo mismo: creo que voy acercándome (al menos eso procuro) a escribir en el tono de la conversación y aspiro a que mis artículos - mientras no puedan ser sustanciales - sean conversaciones con amigos". En la misma carta hay una referencia a su novia; y agregaba, sin duda pensando en ella también: "No abandono mi deseo de irme a la Argentina, aunque las circunstancias me obliguen a esperar".

El 23 del mes siguiente me escribió de nuevo: "Aunque no tengo noticias de usted, después del envío de Mi España, creo tener en usted uno de mis mejores amigos argentinos, y por eso me atrevo a molestarlo. Por ahora, a reserva de escribirle más despacio, le envío la primera de las Cartas a mi tierra, que deseo dar a conocer en la Argentina, y que enviaré en serie. Tengo mi escrúpulo y por eso acudo a usted: no sé dónde encajará mejor la serie, ya que hago afirmaciones que pueden tomarse como excesivas. Le ruego, pues, que usted de- 
cida dónde es preferible que aparezcan las Cartas y las entregue al diario o revista que escoja". Recibí, en efecto, el trabajo anunciado - primero y único- y lo entregué a la revista El Hogar, de Buenos Aires, donde apareció.

Los acontecimientos políticos de México arrasaron en seguida con la situación de aquel momento, y Henríquez Ureña perdió su cargo en el Instituto de Intercambio Universitario. Me escribió una carta angustiosa; recién casado, quedaba sin apoyo económico, en un medio hostil y con sus amigos también desalojados y desvalidos. Necesitaba salir de México y pensaba con más vehemencia que nunca en la Argentina. Pero ¿cómo vivir en ella? ¿Podría conseguir algún puesto público, alguna cátedra para contar con un sostén inicial?

Felizmente estábamos empeñados en la reforma del plan de estudios del Colegio Nacional platense y yo formaba parte del Consejo Superior universitario. El presidente de la Universidad, doctor Benito Nazar Anchorena, y el rector de aquel establecimiento, mi ex alumno doctor Luis H. Sommariva, acogieron mi pedido con simpatía y recta comprensión: el humanista dominicano podía ser un colaborador valioso. Tuve, pues, la alegría de ofrecer a mi lejano amigo tres cátedras secundarias de lengua castellana. Me escribió el 4 de diciembre: "Hoy he recibido su carta del 3 de noviembre y me apresuro a contestarle. Le agradezco infinito sus gestiones y quisiera poder irme en seguida. Pero las circunstancias me lo impiden, así es que le ruego resuelva con las autoridades escolares lo siguiente: $i$ es posible que llegue yo en mayo o junio? Sé que es pedir demasiado, pero otra cosa es imposible para mí y quizás fuera factible encomendar los cursos interinamente a otras personas. Esto implicaría una gran cortesía, excesiva para quien todavía no ha podido iniciar sus cursos, pero no inconveniente para los sustitutos, puesto que recibirán la remuneración entretanto. Las circunstancias que me detienen son éstas: la primera es que precisamente a principios de marzo espero al primogénito. Si pudiéramos emprender el viaje inmediatamente la dificultad no sería tan grande y el niño sería argentino. Pero de momento no veo modo de reunir dinero para el viaje ni me atrevo a dejar abandonados mis embrolladísimos intereses. La situación económica de México 
es muy mala; nadie tiene dinero; mis ahorros están metidos en tierras no acabadas de pagar, y éstas me representan, por ahora, deudas y no entradas. Ni hay a quién vender, ni siquiera a quién asociar. Pero claro es que de aquí a marzo habré logrado darle alguna solución al asunto".

En la misma carta se refería a la muerte de Héctor Ripa Alberdi, acaecida en La Plata el 18 de octubre de aquel año, y el párrafo terminaba con esta vinculación imprevista: "Aquí la Secretaría de Educación Pública organizó una velada a su memoria, y en ella me tocó hablar. Creo, por cierto, que mis palabras al aludir al conflicto universitario de la Argentina ahondaron mi separación de las autoridades mexicanas".

Pedro Henríquez Ureña, su joven y bella esposa y su hijita Natacha desembarcaron en Buenos Aires a fines de junio o principios de julio de 1924. Pedro había gastado en el largo y costoso viaje todo su dinero y se vio obligado a afrontar, durante los primeros meses, una situación penosa, sobre todo para su delicadeza moral. Deseaba instalarse en alguna pensión familiar, y la buscamos juntos. Se decidió por una situada en la calle Bernardo de Irigoyen, bastante próxima a la estación Constitución, y empezó a viajar diariamente; algunas veces lo hacíamos en el mismo tren. Fue recibido con gentileza por las autoridades del Colegio, pero varios profesores de la misma asignatura que él enseñaba, mostraron cierto desapego hacia el nuevo colega: tal vez encono para el "extranjero" recién venido que había logrado una posición envidiable, no alcanzada por ellos en largos años de ejercicio docente; quizás la sequedad un poco hosca del compañero ilustre, que debieron de interpretar como signo de superioridad despectiva, cuando no era sino reserva natural y hasta apocamiento en el trato social. También se esperaría de él la efusión de un tropicalismo desbordante, porque una vez, en la sala de profesores del vasto establecimiento, alguien lanzó en su presencia una saeta intencionada contra la hojarasca literaria de las tierras calientes. Con energía, pero sin destemple, el antillano consideró aquella generalización un lugar común de la ignorancia, y citó escritores ampulosos de regiones mucho menos cálidas de América. Hubiera podido presentarse él mismo como ejemplo de contención y sobriedad. Comprendí entonces 
que el difundido concepto climático influía obsesivamente en su constante vigilancia del estilo. $\mathrm{Y}$ algo después supuse que el resquemor del episodio había aflorado en cierto párrafo de uno de sus trabajos de aquellos días, del que me limito a trascribir estas líneas: "Cada país, o cada grupo de países -está dicho- da en América matices especiales a su producción literaria: el lector asiduo los reconoce. Pero existe la tendencia, particularmente en la Argentina, a dividirlos en dos grupos únicos, la América mala y la buena, la tropical y la otra, los petits pays chauds y las naciones "bien organizadas". La distinción, real en el orden político y económico — salvo uno que otro punto crucial, difícil en extremo-, no resulta clara ni plausible en el orden artístico". ${ }^{1}$

Inmediatamente se impuso por su saber. Asombraba la precisión de su memoria y el interés que manifestaba por conocimientos extraños a sus estudios habituales. Mi amigo inolvidable, el doctor Hilario Magliano, director del departamento de física y matemáticas del Colegio, me confirmaba lo referente a su especialidad: las preguntas que le hacía revelaban una sólida información. Pronto se vinculó a la ciudad universitaria mediante lecturas y conversaciones que grupos de estudiantes o asociaciones de cultura le pedían. En noviembre de 1924 el pintor platense Emilio Pettoruti, recién llegado de Europa después de una provechosa ausencia de diez años, inauguró la exposición de sus cuadros en la Universidad. Yo debí pronunciar las palabras de apertura; impedido por una enfermedad repentina, me reemplazó con ventaja Henríquez Ureña. Destaco de sus páginas esta declaración valiosa: "Si yo he ejercido - con intermitencias, y cada vez menos - la crítica literaria, he esquivado todo lo posible la crítica de artes plásticas, tal vez porque aspiro a persistir en la máxima libertad de mis gustos; creo que en las artes plásticas, aun más que en las letras, ha de ser permanente el reconocer las altas cualidades, pero han de variar en cálida fluidez las preferencias si se quiere que conserven realidad y vida. Si Emilio Pettoruti me cree capaz de hablar de su obra al público de su ciudad natal -y ya reincide-, es sólo porque juzga que los libros y los

iI "Caminos de nuestra historia literaria", en la tevista Valoraciones, tomo II, n. 6, La Plata, junio de 1925. 
museos no me han robado la facultad de pensar, ni siquiera la aptitud para ver"."

El cansancio del viaje diario y la obligación de madrugar lo decidieron a instalarse en La Plata; hubo, tal vez, otra razón poderosa: su necesidad socrática de continuar el diálogo con los alumnos predilectos, después de clase. Solía vérsele con tres o cuatro de ellos por calles y paseos; supe que las reuniones en su casa se prolongaban hasta después de medianoche. Yo almorcé en ella algunas veces, solamente con Pedro e Isabel, su esposa. En una ocasión, de sobremesa, mi amigo me propuso organizar en colaboración una antología poética hispanoamericana. Esta obra lo tentaba desde que en 1910 había participado en la Antología mexicana del centenario con Luis G. Urbina y Nicolás Rangel. Trabajamos varios meses sobre un plan suyo; abandonamos temporariamente, no recuerdo por qué, nuestra labor; la reanudamos en Buenos Aires, cuando él volvió a radicarse en esta ciudad, y finalmente, con motivo de su viaje a Santo Domingo, quedó interrumpida para siempre. Tengo presente que habíamos escogido numerosas piezas y escrito veinte o treinta notas bibliográficas. La admirable memoria de Pedro anticipó el texto inhallable de dos o tres poesías antillanas; verifiqué después su exactitud. Amaba los versos y nunca citaba uno solo sin adoptar la entonación reverente que lo destacara en la espontaneidad descuidada de la charla.

La atracción de Buenos Aires - teatro, conferencias, exposiciones-, el reclamo de sus amistades porteñas y otras tareas docentes ya iniciadas en la gran ciudad, lo devolvieron a ella con su mujer y sus dos hijas, argentina la segunda. Sin embargo, continuó viajando casi diariamente, pues siempre mantuvo, como he dicho, sus tres cátedras en el colegio platense, fuente principal de sus recursos, aunque obligación dura y monótona. Llegaba al tren en el último instante con su cartera abultada, y empleaba la hora de viaje en corregir los trabajos de sus alumnos de segundo y tercer años, o en dormitar, eterno deudor del sueño sacrificado al estudio, a la velada entre amigos, al Colón. Hallaba tiempo, sin embargo, para escribir un

2 "Sobre la obra pictórica de Emilio Pettoruti", en Valoraciones, tomo II, n. 5, La Plata, enero de 1925 . 
artículo o dar una conferencia, y entre éstos no olvido su espléndida colaboración al ciclo de difusión cultural que como rector del Colegio Nacional de La Plata organicé en 1929. Le correspondió a Henríquez Ureña la disertación octava y nos leyó un estudio sobre Música popular de América, que fue convenientemente ilustrado por una pianista y una cantante. Ese estudio de cincuenta y siete páginas impresas, nunca reproducido, yace casi ignorado en el volumen de limitada circulación que recogió aquellas disertaciones. ${ }^{3}$ Al prepararlo para el libro, el autor le añadió notas bibliográficas y aclaratorias y ampliatorias. He aquí el principio de su breve introducción:

Que el título escogido para mi disertación sea mi defensa: Música popular de América no me compromete a hablar de toda la música de nuestra pareja de continentes: me permite limitar el campo. Ya en el camino de las limitaciones, resulta fácil la primera: no hablar del Río de la Plata; no llevar lechuzas a Atenas ni naranjas al Paraguay. Era natural, además, declarar la separación -a pesar de ligeros contactos y coincidencias-entre nuestra América latina y la América inglesa. Era difícil penetrar en la maravillosa selva del Brasil. Y así, de exclusión en exclusión, porque la variedad de países y regiones multiplica las dificultades, llegué a la limitación definitiva: tratar sólo de la música de las Antillas y de México.

Quede también transcrita aquí la diferencia entre el arte popular y el vulgar, tan nítidamente establecida en aquella introducción :

Está en crisis el arte popular genuino: en muchos países - los de nuestra América española entre ellos- va camino de desaparecer. Es una forma de cultura que expresa el sentido de la tierra. Hay quienes la consideran cultura arcaica, que guarda, empobrecidos, los restos de formas superiores, nacidas en la alta cultura: así, las reliquias de la música litúrgica de la Edad Media en la canción popular de diversos pueblos de Europa. Pero el arte popular no es sólo conservación: transforma cuanto adopta, lo acerca a la tierra; además, crea. Como actividad espiritual genuina, es creación.

El arte popular se refugia ahora en los campos, y hasta allí lo persigue y lo acosa el arte vulgar, industria de las ciudades,

3 Conferencias, primer ciclo, volumen I, pp. 179-236, La Plata, 1930. 
especialmente de las capitales. Nunca es obra del hombre sencillo sino del que ha entrado a medias en la cultura, que olfatea la moda y mezcla, en dosis variables, según los casos, heces de civilización y espumas de pueblo. El arte vulgar se extiende desde los cuadros de pintores en boga, los Bouguereau de ayer o los Chabas de hoy, hasta los cromos de almanaque; desde las novelas académicas de Henry Bordeaux y de Ricardo León hasta el sainete de humildes teatros de barrio; desde las óperas triviales que en los grandes escenarios alternan con Don Juan, con Tristán e Isolda, con Boris Godunov, con Peleas y Melisanáa, hasta los cuplés de revista.

No que el arte vulgar merezca siempre desdén: tiene, se ha dicho, sus aciertos, y tantos más cuanto más se acerca a las formas populares. En música los aciertos son más frecuentes que en otras artes: porque las melodías y los ritmos del pueblo se insinúan fácilmente en los gustos del hombre de ciudad y el músico los lleva incorporados a su sensibilidad desde la infancia, mientras que las formas ingenuas de las artes plásticas y de la poesía tropiezan con graves resistencias en el ambiente urbano. El gran pecado del arte vulgar no es que pueda errar: yerra también el arte culto; yerra el popular, aunque no lo crean los idólatras del estado de naturaleza. El gran pecado lo lleva en su fuerza de destrucción, que lo empuja a cegar las fuentes mismas en que bebe mejor: terrible paradoja. La música de jazz, que se nutre de invenciones del campesino negro, extraídas del Sur de los Estados Unidos, al refluir sobre la región creadora va matando en los antiguos esclavos el don de inventar; el tango, irradiando desde Buenos Aires, arrincona y desaloja a las danzas criollas del interior de la Argentina. ¡Lamentable visión, la del futuro en que las artes populares hayan perecido bajo la opresión de la imprenta, el cinematógrafo y la radiotelefonía, invenciones de genio esclavizadas para servix de instrumentos a la mediocridad presuntuosa! Mientras tanto el arte culto se refugiará en atmósferas enrarecidas, perdiendo calor y sangre...

Probemos a atajar tales desastres: llevemos nuestro óbolo a la empresa de salvación, como llevan sus tesoros Albéniz y Falla, Igor Stravinski y Bela Bartok.

La esperanza de poder aliviarse un día de la esclavitud que le representaba corporal y espiritualmente el viaje y la enseñanza secundaria, era una cátedra en la Universidad de La Plata. Como primer paso para llegar a ella le propuse que optara a la suplencia de una de las mías en la Facultad de Humanidades. Obtuvo ese cargo; dictó anualmente las clases reglamentarias e integró las mesas examinadoras; pero una 
resolución del Consejo Académico dispuso que sólo podrían ser profesores titulares los argentinos nativos y los extranjeros naturalizados. Henríquez Ureña creyó que la ordenanza le estaba particularmente dirigida, y como nunca pensó en obtener carta de ciudadanía argentina, no pudo llegar a la titularidad en ninguna cátedra de aquella casa de estudios. También fue profesor suplente de la cátedra de literatura hispanoamericana en la Facultad de Filosofía y Letras de Buenos Aires, y juntos formamos repetidas veces tribunales examinadores; pero aunque no se le opuso allí el impedimento de la nacionalidad, tampoco llegó a ser titular, no obstante haberse producido la vacancia del cargo y corresponderle el mismo. En cambio, fue incorporado al Instituto de Filología, de dicha Facultad, dirigido por el doctor Amado Alonso, su amigo y colaborador en obras didácticas, y realizó trabajos de gran mérito que editó dicho Instituto.

Más suerte tuvo, como docente, en el Instituto del Profesorado Secundario de Buenos Aires. Desempeñó con autoridad indiscutida la cátedra de literatura hispanoamericana y conquistó siempre la devoción de sus alumnos. Como yo pertenecía al establecimiento y tenía a mi cargo materia afín a la suya, constituíamos mesa examinadora común. Hacia la terminación del año lectivo de 1931, Pedro me dijo que el gobierno de su país lo había designado para ocupar el Ministerio de Educación y que anhelaba desempeñar esa función como un deber patriótico, pero que no se decidía a comprometer la estabilidad de su situación docente en la Argentina. Ignoro si se proponía permanecer corto tiempo en su tierra o si temía que las fluctuaciones políticas pudiesen obligarlo a abandonar pronto el ministerio, y él no ignoraba la anomalía que significaba obtener licencia en sus cátedras argentinas para ir a desempeñar una función de aquella naturaleza en su país de origen. La proximidad de las vacaciones allanó temporariamente la dificultad; logróse adelantar el examen de sus alumnos, y partió. El 20 de noviembre recibí carta suya, escrita a bordo del Eastern Prince, frente a Santos. Me decía:

De Rosario le había escrito unas líneas, pero, como usted supo, no nos pudimos embarcar allí. El trastorno sirvió para 
que conociéramos la ciudad y muestras asombrosas de generosidad argentina. Regresamos por unos días a Buenos Aires, y cuando esperaba ocuparme de los amigos, se nos enfermó Natacha de enterocolitis y al fin tuvimos que embarcarnos con ella todavía enferma. Ahora el mar y el reposo nos han mejorado a todos. Espero llegar a Santo Domingo con normalización general.

De Santo Domingo, mientras ejercía el cargo de superintendente general de Enseñanza, me escribió el 16 de febrero de 1932 la tarjeta que transcribo:

Desde que llegué aquí caí en el vórtice, como habría dicho un romántico, y tengo muy pocos minutos fuera del trabajo. La Superintendencia, con escaso personal, atiende las necesidades de una población que parece estar en 1.200,000 habitantes. No he querido comenzar con grandes reformas: hay crisis, y toda reforma cuesta algo. He obtenido ya, sin embargo, una disposición del Consejo Nacional de Educación que, si no suprime los exámenes, exime de ellos a los mejores alumnos, como en la Argentina; he acortado los períodos de exámenes y aumentado el número de clases. Hemos organizado, con profesores que trabajamos gratis, la suspendida Facultad de Filosofía y Letras. He visitado el interior del país (yo sólo conocía siete puertos) y me ha sorprendido el aspecto continental, no isleño, de sus montañas y valles: acaso único en las Antillas, porque tenemos las alturas (hasta 3,140 metros) mayores de todo el archipiélago; Santo Domingo tiene forma de tortuga mientras que Cuba es larga y llana. He dado, además, muchas conferencias.

\section{$\mathrm{Y}$ terminaba:}

He pedido licencias en el Colegio y en el Instituto. Si usted puede influir favorablemente, se lo agradeceré.

Resuelto así el pedido para las cuatro cátedras, el profesor dominicano volvió a ellas al terminar las licencias.

A sus tareas docentes añadió la dirección de una sección de las ediciones Losada: "Cien obras de la literatura y del pensamiento universal". Escogía las obras, escribía para cada una varias páginas de introducción - nunca meras noticias, a veces notables resúmenes de la crítica universal, como en La Ilíada, o estudios sobrios y luminosos, como al frente de Facundo- y además corregía escrupulosamente las pruebas. 
Recuerdo haberle visto aprovechar minutos, entre dos turnos de exámenes, para revisar las galeradas húmedas. Pero su siempre soñada historia de la literatura hispanoamericana -iquién, sino él, era el llamado a dárnosla!- esperaba... Me habló de ella cuando nos conocimos; nuestra antología frustrada debió de estar dentro del mismo plan; poco antes de morir le oí lamentarse de no poder consagrarle el tiempo y la exclusividad necesarios. No hay duda que innumerables apuntes, artículos, disertaciones, y sus clases semanales de la materia iban clarificando, distribuyendo y dando forma parcial a sus enormes acumulaciones; y no todo se perdió, pues sus dos últimos libros fueron extraídos de tan rica experiencia y de tan valiosos yacimientos.

Trabajaba sin biblioteca propia, lo que contribuía a la dispersión del esfuerzo y a la pérdida de muchas horas. Sus mejores libros habían quedado en Santo Domingo, en Cuba, en México, en poder de sus hermanos y sus amigos. Solía referirse a obras difíciles de reemplazar, anotadas por su mano, que había dejado en aquellos países, y tengo muy presente su nostalgia de bibliófilo al evocar un ejemplar suyo de la primera edición de André Chénier, que tenía en La Habana. En repetidas ocasiones, cuando debía dictar las clases anuales correspondientes a la suplencia de mi asignatura en la Facultad de Humanidades, con temas de mi programa, pasó horas en mi casa, entre mis libros, tomando los apuntes que necesitaba. Conservo esos ejemplares con la huella de su lectura: un punto dejado por el lápiz en los márgenes para señalar una línea o un párrafo. Sé que era su costumbre, porque en obras que me facilitó o regaló, descubrí esa guía perceptible pero diminuta. A veces subrayaba una palabra. Y poseo un libro que él debió de pedirme cuando trabajábamos en la abandonada antología - pues se trata de la Antología de poetas modernistas americanos, organizada por C. Santos González y prologada por Rufino Blanco Fambona, edición Garnier Hermanos, París, 1913-que en la página XVIII del prólogo muestra una anotación marginal de tres palabras con su letra. Fue probablemente, una reacción de fastidio, un impulso de réplica aleccionadora. El párrafo apostillado se refiere al poeta mexicano Salvador Díaz Mirón y dice así: "Su personali- 
dad potentísima e inconfundible ha troquelado en su nueva manera una estrofa de ocho heptasílabos; el cuarto, agudo, rimando con el octavo, los tres primeros rimando entre sí, y los quinto, sexto y séptimo también monorrimos. Ya le han imido la estrofa, Rubén Darío el primero". El sabio lector de mi ejemplar anotó al lado de la ligera afirmación: "El viejísimo céjel!" Como es sabido, Henríquez Ureña mantuvo siempre su devoción a la poesía del gran lírico nicaragiüense.

El autor de La versificación irregular en la poesía castellana (Madrid, 1920), tenía evidente predilección por los estudios métricos, que no abandonó durante su residencia en la Argëntina. Entre sus trabajos platenses figura uno de 1926 titulado En busca del verso puro;4 casi veinte años después amplió notablemente el iniciado en 1909 sobre El endecasílabo castellano, ${ }^{5}$ y guardo una carilla de 1945 en que su mano anotó varios trabajos en inglés y en alemán sobre el soneto de Lope de Vega, que no recuerdo si correspondía a investigaciones que hubiera iniciado en los últimos años.

Una tarde, mientras tomábamos exámenes y él presidía, me deslizó un sobre a escondidas; el brillo que sorprendi en sus ojos confirmaba la sorpresa: era la invitación de Harvard a ocupar con un curso de su especialidad la cátedra Charles Eliot Norton, de prestigio mundial, que había contado en años anteriores con las presencias del helenista Gilbert Murray, del físico Alberto Einstein, del músico Igor Stravinsky. El profesor Pedro Henríquez Ureña permaneció en los Estados Unidos durante el año académico 1940-1941. A su regreso, las ocho conferencias dadas por él, en lengua inglesa, en el Fogg Museum of Art, fueron reelaboradas en Buenos Aires y constituyeron el volumen titulado Literary currents in Hispanic America (Cambridge, 1945). La obra, traducida al español por Joaquín Díez-Canedo, apareció impresa en México en 1949.

4Valoraciones, números 10 y 11.

5 Fue publicado en el número 49 del Boletín de la Academia Argentina de Letras - corporación de la que el autor era miembro desde 1934- con esta nota: "El presente trabajo es, en parte, reconstrucción de uno anterior, publicado en la Revista de Filología Española, de Madrid, 1919, y, en parte, enteramente nuevo, especialmente en la porción dedicada a las formas contemporáneas del verso". La primera redacción, fechada en 1909, había sido incluida en el libro iuvenil Horas de estudio, París, 1910. 
Tres años antes, el 11 de mayo de 1946, el autor se había dormido, para no despertar, a mediodía, en un tren que lo llevaba a sus cátedras platenses. La cartera abultada, llena de ejercicios gramaticales, minuciosamente corregidos por el humanista que enterraba horas preciosas en esa labor cotidiana, quedó a su lado, testigo indiferente.

RAFAEL Alberto ARrieta

Academia Argentina de Letras, Buenos Aires, Argentina. 